\title{
Erratum to "Panel Misalignment Effects on the Radiation Pattern from a Solid Surface Deployable Antenna”
}

Seung Joo Jo ${ }^{1} \cdot \mathrm{Ji}^{-}$Yong Lee ${ }^{2} \cdot$ Seong Sik Yoon ${ }^{3} \cdot$ Taek-Kyung Lee ${ }^{1, *} \cdot J_{a e}$ Wook Lee ${ }^{1}$

In the paper entitled "Panel Misalignment Effects on the Radiation Pattern from a Solid Surface Deployable Antenna (Journal of Electromagnetic Engineering and Science, vol. 19, no. 4, pp. 253-258, 2019)", a typographical error occurred in equation (8). The correct equation follows:

$$
S_{ \pm}=I_{0}(j \psi) \pm L_{0}(j \psi)
$$

${ }^{1}$ School of Electronics and Information Engineering, Korea Aerospace University, Goyang, Korea.

${ }^{2}$ Agency for Defense Development, Daejeon, Korea.

${ }^{3}$ Hanwha Systems, Yongin, Korea.

"Corresponding Author: Taek-Kyung Lee (e-mail: tklee@kau.ac.kr)

This is an Open-Access article distributed under the terms of the Creative Commons Attribution Non-Commercial License (http://creativecommons.org/licenses/by-nc/4.0) which permits unrestricted non-commercial use, distribution, and reproduction in any medium, provided the original work is properly cited.

(c) Copyright The Korean Institute of Electromagnetic Engineering and Science. 